\title{
Ductal adenocarcinoma of the pancreas: Expression of growth factor receptors, oncogenes and suppressor genes, and their relationship to pathological features, staging and survival
}

\author{
ANTONIO LOZANO-LEON ${ }^{1}$, BEGONA VIEITES PEREZ-QUINTELA ${ }^{2}$, JULIO IGLESIAS-GARCÍA ${ }^{1}$, \\ JOSE LARIÑO-NOIA ${ }^{1}$, EVARISTO VARO ${ }^{3}$, JERONIMO FORTEZA ${ }^{2}$ and J. ENRIQUE DOMÍNGUEZ-MUÑOZ \\ Departments of ${ }^{1}$ Gastroenterology and Foundation for Research in Digestive Diseases, ${ }^{2}$ Pathology, and \\ ${ }^{3}$ General Surgery, University Hospital Santiago de Compostela, c/Choupana s/n. Santiago de Compostela, Spain
}

Received June 28, 2010; Accepted November 10, 2010

DOI: $10.3892 / \mathrm{ol} .2010 .206$

\begin{abstract}
Pancreatic ductal adenocarcinoma results in high short-term mortality despite recent advances in diagnostics, surgery and chemotherapy. Modern chemotherapeutic agents directed to specific tumor receptors have higher therapeutic efficacy and lower adverse effects. However, few studies exist that evaluate the clinical impact in pancreatic cancer. The expression of tumor growth factor receptors, oncogenes and tumor suppressor oncogenes in surgical pancreatic cancer specimens as related to pathological characteristics, staging and prognosis was evaluated. Data were recorded for 50 patients who underwent a pancreatic cancer resection and were suitable for immunohistochemical evaluation (32 male, mean age 61 years, range 44-78) with regard to pTN, tumor size and location, histological differentiation grade, vascular and perineural invasion, adjuvant chemotherapy and survival time. Tumor specimens and normal pancreatic tissue were deparaffinized and the expression of vascular epidermal growth factor (VEGF) receptors (R)-1 and -2, epidermal growth factor receptor (EGFR), Her-2/neu, COX-2, p16, p21 and p53 was immunohistochemically evaluated using tissue microarrays. Associations between molecular marker expression and clinicopathological tumor characteristics were evaluated using the Chi-square test (SPSS) and the survival time was defined. The Kaplan-Meier method was utilized to analyze survival curves, verified by the log-rank test. No molecular markers evaluated were expressed in normal tissue. Tumor expression data included VEGF-R1 (74\%), EGFR (52\%), Her-2/neu (7.84\%), COX-2 (21.5\%), p16 (29.4\%), p21 (21.7\%) and p53
\end{abstract}

Correspondence to: Dr Antonio Lozano-Leon, Department of Gastroenterology and Foundation for Research in Digestive Diseases, University Hospital Santiago de Compostela, c/Choupana s/n. Santiago de Compostela 15706, Spain

E-mail: antoniolozan@gmail.com

Key words: pancreatic ductal adenocarcinoma, vascular endothelial growth factor receptor, epidermal growth factor receptor, p53
(50\%). Tumors expressing VEGF-R1, EGFR and/or p53 were larger $(p<0.02)$, frequently poorly differentiated $(p<0.05)$ and more frequently associated with perineural and lymph node invasion $(\mathrm{p}<0.05)$. Marker expression did not correlate with pathological tumor characteristics. The median post-surgery survival was 15 months; 60 and $27 \%$ patients survived to 12 and 24 months, respectively, with a longer survival time in patients receiving adjuvant chemotherapy $(n=20)$ (median 36 vs. 15 months, $\mathrm{p}<0.02$ ). Growth factor receptors, oncogenes and tumor suppressor genes were frequently expressed in pancreatic cancer tissue. VEGF-R1, EGFR and p53 expression were associated with poor tissue differentiation and perineural and lymph node infiltration. Only VEGF-R1 expression was associated with a longer survival time and a more favorable response to adjuvant chemotherapy.

\section{Introduction}

According to statistics from the 2005 Spanish Agency of Cancer, pancreatic cancer ranked 7th and 5th in incidence among cancers in males and females, respectively, and the rates are on the increase (1). Smoking, high-calorie diets, certain chemical exposures, chronic pancreatitis, cystic fibrosis and diabetes are known to induce pancreatic cancer. However, the exact cause has yet to be elucidated.

Pancreatic cancer is associated with a poor prognosis, even after curative resection, due to the low resection rates and late diagnosis. Only $15-20 \%$ of patients undergo resection and the 5 -year survival rate is approximately $20 \%$ (2). In addition, adjuvant therapies have yet to be standardized.

Carcinogenesis in the pancreas is a process that involves various factors in DNA, RNA and protein synthesis. Previously, mutation of the tumor suppressor gene and oncogenes (Her-2/neu, COX-2, p16, p21 and p53) was reported as one of the frequent genetic alterations in pancreatic carcinoma (3). An increased expression of the epidermal growth factor receptor (EGFR) and vascular epidermal growth factor receptors (VEGFs) in malignant pancreatic neoplasm has also been noted (4). However, the patterns of expression or co-expression of these markers and their relationship with clinicopathological data remain unclear. 
Table I. Data on immnunohistochemical markers.

\begin{tabular}{llll}
\hline Biomarker & \multicolumn{1}{c}{ Clone } & \multicolumn{1}{c}{ Company } & Dilution \\
\hline p16 & EGH4 & Mtm (molecular tools in medicine) & $1: 25$ \\
p21 Waf/Cip1 & CP-74 Isotype mouse IgG & Sigma & $1: 100$ \\
p53 & DO-7 & Novocastra & $1: 20$ \\
Her2/neu & K & Dako & $1: 10$ \\
COX-2 & COX-2 & Cayman Chemical & $1: 50$ \\
VEGF-R1 & SC-316 & Santa Cruz Biotechnology & $1: 1,000$ \\
VEGF-R2 & SC-6251 & Santa Cruz Biotechnology & $1: 2,000$ \\
EGFR & EGFR.113 & Novocastra & $1: 10$ \\
\hline
\end{tabular}

In the present study, the expression of VEGF receptors (R)-1 and -2, EGFR, Her-2/neu, COX-2, p16, p21 and p53 was compared in tumoral and normal tissue using tissue microarrays (TMAs). The principal aim was to detect the effect of patterns of expression in the prognostic survival of the patients included in this study.

\section{Materials and methods}

Patients and tissue samples. A total of 50 patients were included in the study, 32 of whom were male $(63 \%)$ and 18 female (37\%). Histopathology, tumor stage and survival time were based on the original histopathology reports and patient clinical records. This study was approved by the Ethics Committee of the University Hospital, Santiago de Compostela, Spain. A Tissue Arrayer (Beecher Instruments, Sun Prairie, WI, USA) was used to construct two different TMA blocks, according to the manufacturer's instructions (4). The cases were histologically reviewed and the most representative areas were marked in the paraffin blocks.

Two 1-mm-diameter cylinders selected from two different areas were included in each case from 50 pancreatic ductal adenocarcinomas. The cases were obtained from the files of the Department of Pathology, University Hospital, Santiago de Compostela, Spain. A total of 6 tissue controls were included in each TMA. The TMA blocks were sectioned to produce $4 \mu \mathrm{m}$ sections.

Immunohistochemistry. Immunohistochemical analysis was performed with a universal second antibody kit that used a peroxidase-conjugated labeled-dextran polymer (EnVision, Peroxidase/DAB; Dako, Glostrup, Denmark). A commercially available panel of monoclonal and polyclonal antibodies was used for the following markers: VEGF-R1 and -2, EGFR, Her2/neu, COX-2, p16, p21 and p53. Detailed data on the antibodies are shown in Table I. Only nuclear immunoreactivity was considered positive for p16, p21, p53. Only cytoplasmatic staining showed immunoreactivity for VEGF-R1 and -R2, EGFR, Her2/neu and COX-2. Equivocal staining was considered to be negative. The immunohistochemical results were recorded as positive when $>5 \%$ of the neoplastic cells were immunoreactive. The percentage of positive cells was scored on a semiquantitative scale as: $0,<5 \%$ of positive cells; $1,5-33 \%$ of
Table II. Clinicopathological characteristics of the 50 patients with pancreatic adenocarcinoma.

\begin{tabular}{lr}
\hline Characteristics & No. $(\%)$ \\
\hline Gender & \\
Male & $32(64.00)$ \\
Female & $18(36.00)$ \\
Location & \\
Head & $29(76.30)$ \\
Body/tail & $9(23.60)$ \\
Histological degree & \\
Well differentiated (G1) & $17(35.40)$ \\
Moderately differentiated (G2) & $27(56.20)$ \\
Poorly differentiated (G3) & $4(8.33)$ \\
Tumor size and depth of invasion ${ }^{a}$ & \\
T1 & $9(19.10)$ \\
T2 & $9(19.10)$ \\
T3 & $28(59.50)$ \\
T4 & $1(2.13)$ \\
Lymph node metastasis & \\
Without & $20(42.50)$ \\
With & $27(57.40)$ \\
Stage & \\
IA & $5(10.20)$ \\
IB & $5(10.20)$ \\
IIA & $10(20.40)$ \\
IIB & $28(57.14)$ \\
III & $1(2.04)$ \\
IVA & $0(0.00)$ \\
IVB & $0(0.00)$ \\
Chemotherapy & \\
Without & $30(60.00)$ \\
With & $20(40.00)$ \\
\hline
\end{tabular}

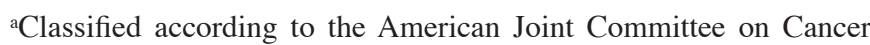
classification.

positive cells; $2,34-66 \%$ of positive cells; and $3, \geq 67 \%$ of positive cells. Staining intensity was graded as: $1+$, weak; $2+$, moderate; and $3+$, strong. 
Table III. Percentage of positive immunohistochemical staining stratified by tumor and normal tissue.

\begin{tabular}{|c|c|c|c|}
\hline Biomarker & Tumoral tissue, $\mathrm{n}=50(\%)$ & Normal tissue, $\mathrm{n}=6(\%)$ & p-value \\
\hline \multicolumn{4}{|l|}{ p16 } \\
\hline Positive & $15(29.4)$ & $0(0.0)$ & \multirow[t]{2}{*}{0.121} \\
\hline Negative & $36(70.5)$ & $6(100)$ & \\
\hline \multicolumn{4}{|l|}{ p21 } \\
\hline Positive & $11(21.7)$ & $0(0.0)$ & \multirow[t]{2}{*}{0.205} \\
\hline Negative & $40(78.4)$ & $6(100)$ & \\
\hline \multicolumn{4}{|l|}{ p53 } \\
\hline Positive & $25(50.0)$ & $0(0.0)$ & \multirow[t]{2}{*}{0.019} \\
\hline Negative & $25(50.0)$ & $6(100)$ & \\
\hline \multicolumn{4}{|l|}{ Her2/neu } \\
\hline Positive & $4(7.84)$ & $0(0.0)$ & \multirow[t]{2}{*}{0.476} \\
\hline Negative & 46 (92.0) & $6(100)$ & \\
\hline \multicolumn{4}{|l|}{ COX-2 } \\
\hline Positive & $11(21.5)$ & $0(0.0)$ & \multirow[t]{2}{*}{0.205} \\
\hline Negative & $40(78.0)$ & $6(100)$ & \\
\hline \multicolumn{4}{|l|}{ VEGF-R1 } \\
\hline Positive & $37(74.0)$ & $0(0.0)$ & \multirow[t]{2}{*}{0.004} \\
\hline Negative & $13(26.0)$ & $6(100)$ & \\
\hline \multicolumn{4}{|l|}{ VEGF-R2 } \\
\hline Positive & $33(65.0)$ & $0(0.0)$ & \multirow[t]{2}{*}{0.135} \\
\hline Negative & $18(35.0)$ & $6(100)$ & \\
\hline \multicolumn{4}{|l|}{ EGFR } \\
\hline Positive & $26(52.0)$ & $0(0.0)$ & \multirow[t]{2}{*}{0.015} \\
\hline Negative & $24(48.0)$ & $6(100)$ & \\
\hline
\end{tabular}

Statistical analysis. Percentage scores of 1,2 and 3 ( $\geq 5$ cells stained) were considered to be positive for the comparison between groups. Correlations between the markers and individual clinicopathological variables were evaluated using the Chi-square test. The survival time was defined as the time since resection surgery to the last contact or until the patient succumbed to the disease. The survival curves were calculated using the Kaplan-Meier method, and the Mantel-Cox log-rank test was used to determine the differences between the curves. The effect of independent binary variables on the incidence of expression markers was calculated using the logistic regression modeling technique. The reported p-values $(p<0.05)$ were considered to be significant. The statistical analysis was performed using the SPSS version 12 software (Chicago, IL, USA).

\section{Results}

Patient characteristics. Table II summarizes the clinical and histopathological findings in our patient population. The cohort includes 50 patients, the majority of whom (75\%) were $>60$ years of age (range 44-78, median 61).

Molecular markers and patient survival. Table III shows the percentage of positive/negative staining in the patients and controls for each marker. When univariate analysis was used, positivity for VEGF-R1 (74\%) was associated with tumoral differentiation degree $(\mathrm{p}<0.05)$, size $(\mathrm{p}<0.02)$ and tumoral location (head, $\mathrm{p}<0.03)$. EGFR immunopositivity $(50 \%)$ was associated with tumor differentiation degree $(\mathrm{p}<0.03)$, size $(p<0.02)$, perineural infiltration $(p<0.02)$ and lymph node metastasis $(p<0.03)$. A significant correlation was observed in p53 expression (50\%) with a degree of differentiation $(\mathrm{p}<0.01)$. The expression of the remaining markers did not correlate with the pathological tumor characteristics. The median survival following surgery was 15 months; $60 \%$ of patients survived to 12 months and $27 \%$ survived to 24 months. Patients who received chemotherapy $(\mathrm{n}=20)$ showed better overall survival times and VEGF-R1 expression (36 vs. 15\% months in positive or negative staining). When using multivariate analysis, the only immunohistochemical marker that affected overall survival was VEGF-R1 ( $<<0.04)$ (Fig. 1). The risk of mortality was 5.86-fold greater (CI 95\%) in patients without VEGF-R1 expression.

\section{Discussion}

Pancreatic ductal adenocarcinoma remains a challenging clinical problem. Resection is the most effective treatment, but it is only applicable in a minority of patients, whereas the remainder of patients present with an advanced stage of the disease and few effective therapeutic options are available. In this study, TMA technology was used to study growth factors, oncogenes and the suppressor gene expression in pancreatic ductal adenocarcinoma in order to establish a common predictor for prognostic survival. 


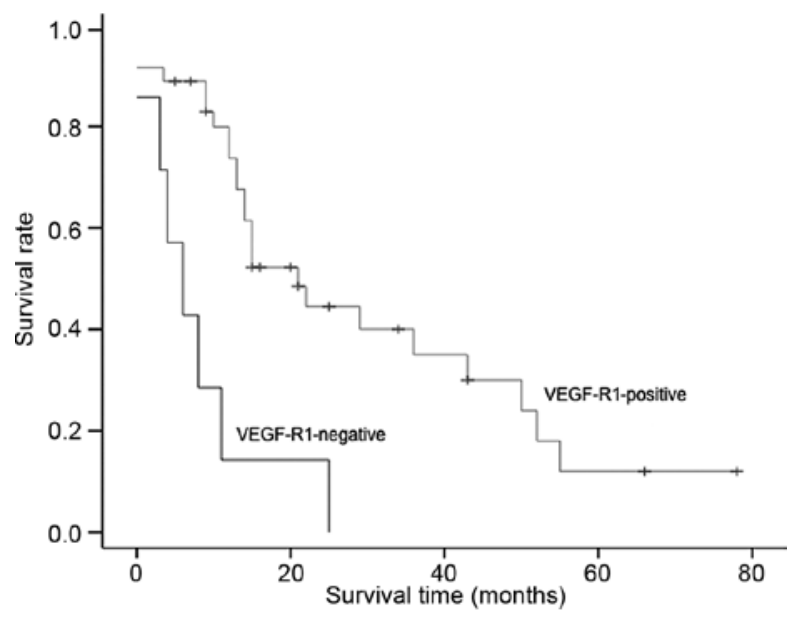

Figure 1. Overall survival curve based on VEGF-R1 expression in 50 pancreatic ductal adenocarcinomas.

The incidence of p16 gene mutation and protein expression in pancreatic cancer were reported to be between 30 and $87 \%$ $(5,6)$, with the wide range possibly caused by a difference in subjects or examination methods. Previous studies showed that, compared to other tissues, pancreatic cancer cell lines expressed p16 gene mutation more (6). However, discrepancies were noted in the findings of these studies due to the mutation study methods and immunohistochemical staining utilized. The results of our study, in which p16 protein expression was detected in $29.4 \%$ of the patients, were similar to those of previous studies. Numerous results have been published regarding the association of the p16 gene with clinicopathological characteristics and the survival rate. Bartsch et al (7) noted that the median survival time of cases with and without p16 expression was 8.5 and 17 months, respectively. However, other studies $(8,9)$, including our study, found no correlation between p16 expression and the survival rate.

The tumor suppressor p53 and the cyclin kinase inhibitor p21 are among the key gene products involved in cell growth arrest, differentiation and senescence. Immunohistochemistry has been used to examine p53 expression in pancreatic adenocarcinoma $(10,11)$. Half of our pancreatic adenocarcinoma patients $(50 \%)$ showed p53 expression in their tumors (inclusive of scores 1,2 and 3). Various studies have proposed contrasting results in the association between p53 mutation and clinicopathological characteristics (8,9,12-14). On the other hand, Yokoyama et al (15) reported a correlation between p53 mutation and clinical stages. In this study, p53 protein expression was correlated to the grade of histological differentiation according to Jeong et al (16).

The p21 expression is compartmentalized in certain post-replicative cell types, including colonic epithelial cells in the upper halves of crypts, and this expression has been associated with the earlier clinical stages of pancreatic cancer. Dergham et al (17) reported p21 expression in 57\% of pancreatic adenocarcinomas. Moreover, it was found to correlate with stage I and II of the disease and poor survival prediction (stage I: p21-negative, 5.9 months; p21-positive, 13.5 months). Our results showed that $22 \%$ of patients exhibited positive immunoreaction for this protein, but we did not find any clinical variable correlation. Further studies are required in order to evaluate whether p21 expression is correlated to survival time differences among patients within each stage.

In pancreatic cancer, $\mathrm{COX}-2$ is considered to be a molecule that plays a key role in tumorigenesis. The COX-2 expression inhibits apoptosis and increases the invasiveness of malignant cells. We found COX-2 expression in 11 out of 50 cancer cases. This expresson is slightly lower than that reported in the literature, which may be as high as 74\% depending on the method used, including Northern and Western blotting as well as immunohistochemical analysis $(18,19)$. Okami et al (20) reported weak staining in the majority of the investigated carcinoma specimens. COX-2 staining in pancreatic carcinoma was extremely heterogeneous and large variations between specimens were noted.

Koshiba et al (21) suggested that for pancreatic carcinoma, COX-2 is associated with the degree of malignancy comparing intraductal papillary mucinous adenomas, intraductal papillary carcinomas and intraductal carcinomas. In our study, a positive or negative correlation between COX-2 expression and the clinicopathological data was not shown.

TheHer-2/neu(c-erb-b2) proto-oncogeneencodes a 185-kDa transmembrane glycoprotein that is closely related in structure to the EGFR and has been found to be amplified and overexpressed in pancreatic tumors $(22,23)$. Hall et al $(24)$ reported that Her-2/neu was detected in the cell cytoplasm of chronic pancreatitis and ductal pancreatic adenocarcinoma. The study by Yamanaka et al (25) also showed the expression of Her-2/ neu in normal acinar and ductal cells. Our study showed a low level of staining in tumor samples (4 out of 50 cases) and no staining in the normal pancreatic tissue. Certain authors have reported that the c-erb-b2 oncoprotein is potentially involved in the proliferative responses of pancreatic epithelium. Dugan et al (26) reported that Her-2/neu expression is rare in tumors that lack glandular differentiation and suggested that the pattern of the Her-2/neu expression is related to glandular differentiation and early oncogenesis.

EGFR belongs to a family of closely related transmembrane proteins, including Her-2/neu (27). Its expression has been reported in 30-50\% of pancreatic carcinomas (28-30). Our results are consistent with these reports. Various data are available regarding the possibility of synergy or other interactions between the products of the c-erb-b2 gene and other growth factor receptors, including EGFR (31). It has been suggested that the co-expression of Her-2/neu and EGFR, at levels that are individually insufficient to transform cells, converts fibroblasts to a completely malignant state (32). It is possible that Her-2/neu and EGFR have a synergistic effect in the carcinogenesis of pancreatic tumors. However, no statistical significance was found regarding this correlation.

The angiogenic system of VEGF and its receptors VEGF-R1 and -2 is linked to the formation of new blood vessels in malignant and non-malignant conditions (33-35). Four VEGF binding receptors have been identified (36-38). Among them, VEGF-R2 (KDR, flk-1) appears to be the most significant since it mediates the mitogenic effects of VEGF on endothelial cells, whereas VEGF-R1 mediates endothelial cell migrations $(36,39)$.

In the present study, VEGF and its receptors were found to be markedly expressed in the human pancreatic cancer 
specimens (R1 74\%; R2 65\%) and were associated with tumor size, tumoral differentiation degree and survival time. In pancreatic cancer, the functional and prognostic significance of VEGF and VEGF-R1 and -2 expression has been investigated. Immunohistochemical analysis if frequently used to show that VEGF was expressed in the majority of types of cancer and that expression, in general, was correlated with a worse outcome and was therefore a marker of a poor prognosis, such as advanced stage $(40,41)$. For example, Itakura et al showed that VEGF mRNA and protein expression in the pancreatic cell lines tested and used immunohistochemical analysis to demonstrate a predominant membrane/cytoplasm localization. The staining results of these authors were confirmed with in situ hybridization studies. However, other studies have produced conflicting results with no correlation with outcome $(42,43)$. Follow-up studies from Itakura et al also confirmed the co-expression of VEGF-R1 and -2 in cultured pancreatic cancer cells lines. Buchler et al (44) demonstrated similar findings. It is noteworthy that their results showed that R2, but not $\mathrm{R} 1$, abrogated the in vitro stimulatory effects of VEGF on pancreatic cancer cell proliferations, suggesting that the growth-promoting effect of VEGF in pancreatic cancer may be dependent predominantly on $\mathrm{R} 2$ rather than $\mathrm{R} 1$.

$\mathrm{R} 1$ has shown a both a positive and negative divergent effect on tumor growth potential. The conflicting literature may reflect the fact that $\mathrm{R} 1$ probably has different roles, depending on the physiological and pathological conditions and the tissue type in which it is expressed. In the present study, a low tumor $\mathrm{R} 1$ expression was associated with decreased survival times and was correlated with advanced disease. This suggests that it has a protective effect and acts as a negative regulator of angiogenesis. Although, in our study, the R1 antibody presumably only detected full-length R1 and not the soluble form, since it identifies the intracellular domain, potential decoy roles for this receptor have been attributed to both forms. Similar results were noted by Chung et al (45).

In conclusion, our study indicates that growth factor receptors, oncogenes and tumor suppressor genes are frequently expressed in pancreatic cancer tissue. The expression of VEGF-R1, EGFR and p53 is associated with poor tissue differentiation and perineural and lymph node infiltration. VEGF-R1 immunopositive staining is associated with longer survival times, related to a more favorable response to adjuvant chemotherapy.

\section{References}

1. Mortalidad por cáncer en España. 2005. www.aecc.es.

2. Crist DW and Cameron JL: The current status of the Whipple operation for periampullary carcinoma. Adv Surg 36: 59-152, 1992.

3. Redston MS, Caldas C, Seymour AB, Hruban RH, da Costa L and Yeo CJ: p53 mutations in pancreatic carcinoma and evidence of common involvement of homocopolymer tracts in DNA microdeletions. Cancer Res 54: 3025-3033, 1996.

4. Garcia JF, Camacho FI, Morente M, Fraga M, Montalban C, Alvaro T, Bellas C, Castano A, Diez A, Flores T, Martin C, Martinez MA, Mazorra F, Menarguez J, Mestre Mj, Mollejo M, Saez AI, Sanchez L, Piris MA and Spanish Hodgkin's Lymphoma Study Group: Hodgkin's and Reed-Stenberg cells harbor alterations in the major tumor suppressor pathways and cell-cycle checkpoints: analyses using tissue microarrays. Blood 101: 681-689, 2003.
5. Googins M, Achutte M, Lu J, Moskaluk CA, Weinstein CL and Petersen GM: Germline BRCA2 gene mutations in patients with apparently sporadic pancreatic carcinomas. Cancer Res 56: 5360-5364, 1996.

6. Huang L, Goodrow TL, Zhang S., Klein-Szanto AJP, Chang H and Ruggeri BA: Deletion and mutation analyses of the p16/ MTS1 tumour suppressor gene in human ductal pancreatic cancer reveals a higher frequency of abnormalities in tumorderived cell lines than in primary ductal adenocarcinomas. Cancer Res 56: 1137-1141, 1996.

7. Moskaluk CA, Hruban RH and Kern SE: P16 and K-ras gene mutations in the intraductal precursors of human pancreatic adenocarcinoma. Cancer Res 57: 2140-2143, 1997.

8. Rozenblum E, Schutte M, Goggins M, Hahn SA, Panzer S and Zaurak M: Tumor-suppressive pathways in pancreatic carcinoma. Cancer Res 57: 1731-1734, 1997.

9. Kawesha A, Chaneh P, Andren-Sandberg A, Ograed D, Skar R and Dawiskiba S: K-ras oncogene subtype mutations are associated with survival but not expression of p53, p16INK4A, p21WAF-1, cyclin D1, erbB-2 and erbB-3 in resected pancreatic ductal adenocarcinoma. Int J Cancer 89: 469-474, 2000.

10. Suzuki T and Takano Y: Comparative immunohistochemical studies of p53 and proliferating cell nuclear antigen expression and argyrophilic nucleoral organizer regions in pancreatic duct cell carcinomas. Jpn J Cancer Res 84: 1072-1077, 1993.

11. Zhang SY, Ruggeri B, Agarwal P, Sorling AF, Obara $T$ and Ura H: Immunohistochemical analysis of p53 expression in human pancreatic carcinomas. Arch Pathol Lab Med 118: 150-154, 1994.

12. Dergham ST, Dugan MC, Kucway R, Du W, Kamarauskiene DS and Vaitkevicius VK: Prevalence and clinical significance of combined K-ras mutation and p53 aberration in pancreatic adenocarcinoma. Int J Pancreat 21: 127-143, 1997.

13. Ruggeri BA, Huang L, Berger D, Chang H, Klein-Szanto AJ and Goodrow T: Molecular pathology of primary and metastatic ductal pancreatic lesions. Cancer 79: 700-716, 1997.

14. Gansauge F, Gansauge S, Schmidt E, Muller J and Beger HG: Prognostic significance of molecular alterations in human pancreatic carcinoma - an immunohistological study. Langenbecks Arch Surg 383: 152-155, 1998.

15. Yokoyama M, Yamanaka Y, Friess H, Buchler M and Murray K: P53 expression in human pancreatic cancer correlates with enhanced biological aggressiveness. Anticancer Res 14: 2477-2483, 1997.

16. Jeong J, Park YN, Park JS, Yoon DS, Chi HS and Kim BR: Clinical significance p16 protein expression loss and aberrant p53 protein expression in pancreatic cancer. Yonsei Med J 46: 519-525, 2005.

17. Dergham S, Dugan M, Joshi U, Chen Y, Du W, Smith D, Arlauskas P, Crissman J, Vaitkevicius V and Sarkar F: The clinical significance of p21 WAF1/CIP-1 and p53 expression in pancreatic adenocarcinoma. Cancer 80: 372-381, 1997.

18. Molina MA, Sitja-Arnau M, Lemoine MG, Frazier ML and Sinicrope FA: Increased cyclooxygenase-2 expression in human pancreatic carcinomas and cell lines: growth inhibition by nonsteroidal anti-inflammatory drugs. Cancer Res 59: 4356-4362, 1999.

19. Kokawa A, Kondo H, Gotoda T, Ono H, Saito D, Nakadaira S, Kosuge T and Yoshida S: Increased expression of cyclooxigenase-2 in human pancreatic neoplasms and potential for chemoprevention by cyclooxygenase inhibitors. Cancer 91: 333-338, 2001.

20. Okami J, Yamamoto H, Fujiwara Y, Tsujie M, Kondo M, Noura S, Oshima S, Nagano $H$, Dono $K$, Umeshita $K$, Ishikawa O, Sakon M, Matsuura N, Nakamori S and Monden M: Overexpression of cyclooxygenase-2 in carcinoma of the pancreas. Clin Cancer Res 5: 2018-2024, 1999.

21. Koshiba T, Hosotani R, Miyamoto Y, Wada M, Lee JU, Fujimoto K, Tsuji S, Nakajima S, Doi R and Imamura $\mathrm{M}$ : Immunohistochemical analysis of cyclooxygenase-2 expression in pancreatic tumors. Int J Pancreatol 26: 69-76, 1999.

22. Williams TM, Weiner DB, Greene MI and Maguire HC: Expression of erbB-2 in human pancreatic adenocarcinoma. Pathobiology 59: 46-52, 1991.

23. Day DJ, Di Giuseppe JA and Yeo C: Immunohistochemical evaluation of Her-2/neu expression in pancreatic adenocarcinoma and pancreatic intraepithelial neoplams. Hum Pathol 27: 119-124, 1996.

24. Hall PA, Hughes CM, Staddon SL, Richman PI, Gullick WJ and Lemoine NR: The c-erbB-2 proto-oncogene in human pancreatic cancer. J Pathol 161: 195-200, 1990. 
25. Yamanaka Y, Friess H and Kobrin MS: Overexpression of Her2/ neu oncogene in human pancreatic carcinoma. Human Pathol 24: 1127-1134, 1993.

26. Dugan MC, Dergham ST and Kucway R: Her-2/neu expression in pancreatic adenocarcinoma: relation to tumour differentiation and survival. Pancreas 14: 229-236, 1997.

27. Sirivatanauksorn V, Sirivatanauksorn Y and Lemoine NR: Molecular pattern of ductal pancreatic cancer. Langenbecks Arch Surg 383: 105-115, 1998.

28. Lemoine NR, Hughes CM and Barton CM: The epidermal growth factor receptor in human pancreatic cancer. J Pathol 166 : 7-12, 1992.

29. Kioppel G, Maillet B and Schewere K: Immunocytochemical detection of epidermal growth factor receptor (EGFr) and transferrin receptor (TR) on normal, inflamed and neoplastic pancreatic tissue. Pancreas 4: 623, 1989.

30. Uegaki K, Nio Y and Inoue Y: Clinicopathological significance of epidermal growth factor and its receptor in human pancreatic cancer. Anticancer Res 17: 3841-3848, 1997.

31. Sterm DF and Kamps MP: EGF-stimulated tyrosine phosphorylation of p185neu a potential model of receptor interactions. EMBO J 7: 995-1001, 1988.

32. Kokai Y, Myers JN and Wada T: Synergistic interaction of p185neu and EGF receptor leads to transformation of rodent fibroblasts. Cell 58: 287-292, 1989.

33. Millauer B, Wizigmann-Voss S and Schunürch H: High affinity VEGF binding and developmental expression suggest Flk-1 as a major regulator of vasculogenesis and angiogenesis. Cell 72 : 835-846, 1993

34. Ferrara N and Henzel WJ: Pituitary follicular cells secrete a novel heparin-binding growth factor specific for vascular endothelia cells. Biochem Biophys Res Commun 161: 851-858, 1989.

35. Gospodarowicz D and Lau K: Pituitary follicular cells secrete both vascular endothelial growth factor and follistatin. Biochem Biophys Res Commun 165: 292-298, 1989.

36. De Vries C, Escobedo JA and Ueno H: The fms-like tyrosine kinase, a receptor for vascular endothelial growth factor. Science 255: 989-991, 1992.
37. Terman BI, Dougher-Vermazen M and Carrion ME: Identification of KDR tyrosine kinase as a receptor for vascular endothelial cell growth factor. Biochem Biophys Res Commun 187: 1579$1586,1992$.

38. Chen H, Chedotal A and He Z: Neuropilin-2 a novel member of the neuropilin family, is a high affinity receptor for the semaphorins Sema E and Sema IV but not Sema III. Neuron 19: 547-559, 1997.

39. Brown JM and Giaccia AJ: The unique physiology of solid tumors. Opportunities (and problems) for cancer therapy. Cancer Res 58: 1408-1416, 1998.

40. Itakura J, Ishiwata $\mathrm{T}$ and Friess $\mathrm{H}$ : Enhanced expression of vascular endothelial growth factor in human pancreatic cancer correlates with local disease progression. Clin Cancer Res 3: 1309-1316, 1997.

41. Seo Y, Baba H, Fukuda T, Takashima M and Sugimachi K: High expression of vascular endothelial growth factor is associated with liver metastasis and poor prognosis for patients with ductal pancreatic adenocarcinoma. Cancer 88: 2239-2245, 2000.

42. Ellis LM, Takahashi Y, Fenoglio CJ, Cleary KR, Bucana CD and Evans DB: Vessel counts and vascular endothelial growth factor expression in pancreatic adenocarcinoma. Eur J Cancer 34: 337-340, 1998

43. Fujimoto K, Hosotani R and Wada M: Expression of two angiogenic factors, vascular endothelial growth factor and platelet-derived endothelial cell growth factor in human pancreatic cancer, and its relationship to angiogenesis. Eur J Cancer 34: 1439-1447, 1998.

44. Buchler P, Peber HA, Buchler MW, Friess H and Hines OJ: VEGF-RII influences the prognosis of pancreatic cancer. Ann Surg 236: 738-749, 2002.

45. Chung G, Yoon H, Zerkowsi M, Ghosh S, Thomas L, Harigopal M, Charette L, Salem R, Camp R, Rimm D and Burtness B: Vascular endothelial growth factor, FLT-1, and FLK-1 analysis in pancreatic cancer tissue microarray. Cancer 106: 1677-1684, 2006. 